\title{
Developing Construction Hazard Database for Automated Hazard Identification Process
}

\author{
Matej MIHIĆ, Anita CERIĆ, Ivica ZAVRŠKI
}

\begin{abstract}
Construction industry is extremely hazardous with construction workers almost three times more likely than average to suffer a fatal accident in the workplace. Although great improvement in safety performance has been noted, in recent years the improvement started stagnating. To tackle this issue and to improve safety on the construction sites, numerous Health and Safety $(\mathrm{H} \& S)$ research is carried out. This research aims to contribute in reducing the number of accidents and consequently injuries by enabling automated hazard identification through the use of Building Information Modelling (BIM) and a specially developed construction hazards database. Goal of this paper is to present the structure and purpose of the database and how construction hazard and activity data was gathered and entered into the database. Sources for the construction hazard and activity identification process included scientific and professional construction $\mathrm{H} \& \mathrm{~S}$ literature as well as specialised construction $\mathrm{H} \& \mathrm{~S}$ documentation. Results presented in this paper are the first step of a research effort to enable automated identification of construction hazards through the use of BIM.
\end{abstract}

Keywords: activity data gathering; BIM; construction hazards database; hazard identification; hazard data gathering; Health and Safety

\section{INTRODUCTION}

Construction industry is a leader in some of the most undesirable statistical categories such as the number of accidents at work and fatal accidents, both in absolute numbers and relative to the number of workers employed in the industry. The exact number of accidents and incidence rates (number of injuries per 100,000 workers in the industry) vary on a country to country basis, with developed countries having smaller numbers than the undeveloped ones, but nevertheless the construction industry is always amongst the most dangerous professions.

According to the International Labour Organization (ILO) accidents in the workplace cause around 321,000 deaths and 317 million injuries worldwide each year [1]. Out of this number, around 60,000 deaths occur at the construction site [2], or $18.7 \%$ of all fatalities. Considering that globally construction industry employs around 6-10\% of the workforce [3] that makes construction workers a lot more likely to suffer a fatal accident than average across all industries. Construction worker safety has improved when compared to ten years ago, but unfortunately improvement has slowed down in recent years, or in some cases even gotten worse [4]. This stagnation can serve as a motivator to further investigate the reasons behind the stagnation of safety improvement and to develop new methods and/or technologies for safety improvement.

\subsection{Motivation and Research Context}

Due to this enormous loss of life, numerous injuries and disabilities which impact not just the immediate stakeholders but the society as a whole, it is not surprising that Health and Safety $(\mathrm{H} \& \mathrm{~S})$ in the construction sector is of interest not just to practitioners and regulators, but to researchers as well. Health and Safety in the construction industry is a propulsive research field with a myriad of scientific papers and books published and research conducted to improve the health and lessen the probability of construction workers' injuries and death.

Topics of researchers' interests have varied throughout the last two decades. Zhou [5] reports that at the beginning the research was mainly concentrated on construction accident data (inclusive of gathering accident statistics, analysing causing factors and calculating accident cost), followed by a change in focus to individual characteristics of site workers, e.g. behaviour, perception, attitude, competency and psychology. During the last 10 years, the focus has again shifted, this time to the application of innovative technologies with a goal to support safety management in the construction industry [5]. Examples of such research are: Design for Construction Safety Toolbox [6], Construction Hazard Assessment with Spatial and Temporal Exposure (CHASTE) [7], Construction Hazard Assessment Implication Review (CHAIR) [8], Construction Job Safety Analysis (CJSA) [9], CAVE Automatic Virtual Environment (CAVE) [10, 11], Construction Safety Ontology [12], Automatic Safety Checking of Construction Models and Schedules [13], Application of geographic information systems in construction safety planning [14], Natural language processing system for automated content analysis [15] and others.

Results presented in this paper are a part of a research effort to enable automated identification of construction hazards through the use of Building Information Modelling (BIM) and is one of the components of a currently unpublished $\mathrm{PhD}$ thesis titled "Incorporation of Health and Safety into Building Information Modelling through Hazard Integration System" [16]. The aforementioned thesis presents the development of a Hazard integration system (System) whose goal is to enable an accurate, quick and efficient way to identify construction hazards which affect workers on the construction sites. The research proposes to do so by combining information already present in BIM models with a specially developed Construction hazards database (Database) to automatically list all possible construction hazards faced by the construction workers.

A short description of how the System would attribute construction hazards to BIM model elements follows. Every BIM model element needs to have defined object type and material. By knowing what element is to be constructed and which material it is constructed of, it can be determined with a high degree of accuracy which construction activities will need to be completed during the element's construction. It can also be ascertained which 
hazards are created by performing work on those activities, thus indirectly attributing the construction hazards to BIM model elements, through the activities needed to construct them.

First step that needs to be completed in that process to enable automated hazard identification is defining and structuring the Database in such a way that it enables realisation of all proposed results. This Database needs to contain all relevant construction hazard and construction process information. Additionally, other requirements upon the database need to be defined, such as how the data is entered, edited and structured in the Database.

As such, the Construction hazards database is only the first step to automated hazard identification, as it is a part of the larger process presented in the $\mathrm{PhD}$ thesis. The System uses the data gathered and structured in the Database to assign construction hazards to workers conducting construction activities on building's elements which are represented by BIM model elements. This paper however, due to the extensiveness of the entire research effort, focuses on the creation and development of the Construction hazard database.

\subsection{Definitions of the Terms Used in the Paper}

Different literature sources focused on different fields of study oftentimes use different names for the same term, or even more confusingly use the same word to describe different terms. To avoid possible confusion, this section will briefly describe the most important and most often mistaken terms. They will be listed in the following paragraphs.

An accident is a chance event with negative outcomes to health and safety of construction workers. This definition is similar to the one presented in the research of Sacks and Rosenfeld [7] who describe an accident as an unintentional event that causes bodily or property damage.

Exposure, according to Sacks and Rosenfeld [7] is defined as the presence of a potential victim (or victims) in a zone that may be affected in an accident scenario. This research accepts their definition, but does however differentiate several types of exposure:
- Temporal exposure - workers are present at the same time as the hazard;

- Spatial exposure - workers are present in the area of the hazard's influence;

- Self exposure - workers expose themselves to hazards (results in self-induced hazards);

- Peer exposure - workers are exposed to hazards produced by other workers (results in peer-induced hazards).

Project management centred literature describes hazard as a potential risk [17]. Construction H\&S literature on the other hand describes a hazard as a potential for harm [4], which may endanger the safety and health of workers [18]. This research describes hazards as potential outcomes of events which may cause ill effects to the safety and well being of construction workers.

Injury is a consequence of a hazard taking place. As opposed to professional illnesses which occur from prolonged exposure to harm, injuries are immediate results of a single accident.

Professional illness is a consequence of adverse influence on a worker's health contracted through sustained exposure to harms or hazards in the workplace. Professional illness is not manifested from one incident, but rather from prolonged exposure to harmful events or substances.

Definitions of risk are numerous but a common element to almost all definitions of risk is that it comprises two independent components: probability and severity [17]. In construction $H \& S$ research risk is defined as the likelihood that harm from a particular hazard will occur and the possible extent of the harm [19]. This research therefore defines risk as a quantified value of the probability of a hazard's occurrence and the severity outcome of the hazard.

Two comprising elements of risk are probability and severity. Probability is the likelihood that a hazard will occur and severity is the measure of significant will the consequence be if the hazard does occur.

\begin{tabular}{|c|c|c|c|c|c|c|}
\hline \multirow[b]{2}{*}{ Element type } & \multicolumn{6}{|c|}{ Material type } \\
\hline & Concrete & $\mathrm{RC}^{*}$ & Masonry & Wood & Steel & $\begin{array}{c}\text { Prefabricated } \\
\mathrm{RC}^{*}\end{array}$ \\
\hline Column & $\mathrm{x}$ & $\mathrm{x}$ & $\mathrm{x}$ & $\mathrm{x}$ & $\mathrm{x}$ & $\mathrm{x}$ \\
\hline Wall & $\mathrm{x}$ & $\mathrm{x}$ & $\mathrm{x}$ & & & $\mathrm{x}$ \\
\hline Beam & & $\mathrm{x}$ & & $\mathrm{x}$ & $\mathrm{x}$ & $\mathrm{x}$ \\
\hline Slab & & $\mathrm{x}$ & & & & $\mathrm{x}$ \\
\hline Foundation & $\mathrm{x}$ & $\mathrm{x}$ & & & & $\mathrm{x}$ \\
\hline Stairway & & $\mathrm{x}$ & & $\mathrm{x}$ & $\mathrm{x}$ & $\mathrm{x}$ \\
\hline Horizontal reinforcement & & $\mathrm{x}$ & & & & \\
\hline Vertical reinforcement & & $\mathrm{x}$ & & & & \\
\hline Lintel & & $\mathrm{x}$ & & & & $\mathrm{x}$ \\
\hline Roof structure & & & & $\mathrm{x}$ & $\mathrm{x}$ & $\mathrm{x}$ \\
\hline
\end{tabular}

Figure 1 Types of materials and model elements

\section{CONSTRUCTION ACTIVITY DATA GATHERING PROCESS}

An important aspect of the Construction hazards database, whose development is presented in this paper, is that it consists of two separate but interconnected parts.
The first one is the Construction process database (containing construction activities) and the second is the Hazard information database (containing construction hazards). Due to the specifics of BIM and BIM authoring software with regard to storing and accessing parametric information construction activities were chosen as an 
intermediary between BIM model elements and hazards rather than entering hazard data straight into BIM. Therefore, the construction activities also needed to be collected for the Database.

This research is currently limited to construction activities needed to construct building's structural elements represented in BIM by these BIM model elements: column, beam, wall, staircase, slab, horizontal and vertical reinforcements, lintels, foundations and roof structures. First step in identifying construction activities was to identify all structural BIM model elements. The second step is to identify all material types the element can be constructed of. For example, columns can be constructed from concrete, reinforced concrete, bricks, wood, steel and prefabricated reinforced concrete. In total, 30 combinations of BIM model elements and materials (presented in Fig. 1) were identified. This identification process is depicted in Fig. 2 for three different elements: wall, slab and beam. Each element is connected to all materials from which it can be constructed. Walls can be constructed out of concrete, reinforced concrete and masonry; slabs can be constructed only of reinforced concrete; and beams can be constructed of reinforced concrete, wood and steel.

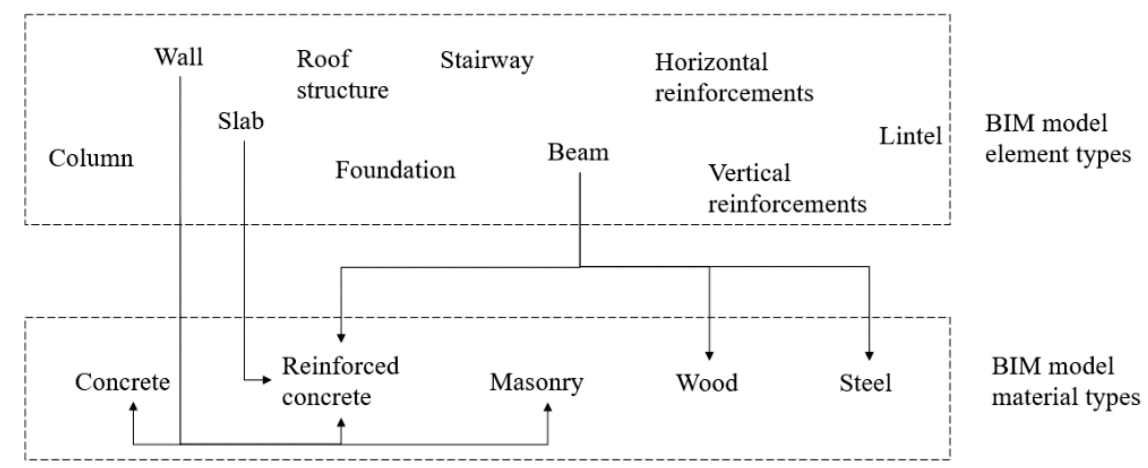

Figure 2 BIM model elements and materials

Third step consists of identifying construction activity work types required for constructing the element for each possible element and material combination. Links between each of the BIM model element type and material combinations for walls and beams, and the construction activity work types needed to construct those two element types are presented in Fig. 3. For instance, for reinforced concrete beams, activities include: placing formwork for the beam, placing the rebar for the beam, concrete pouring and finally formwork removal. Some of the activities are similar for different elements and cause the same hazards no matter which element is being constructed. Concrete pouring, for example, is similar for different element types and rebar placing has the same hazards regardless if the element in question is a slab or a beam. Similarly, formwork construction activities for all horizontal structural elements share the same hazards, as do the formwork activities for all vertical elements.

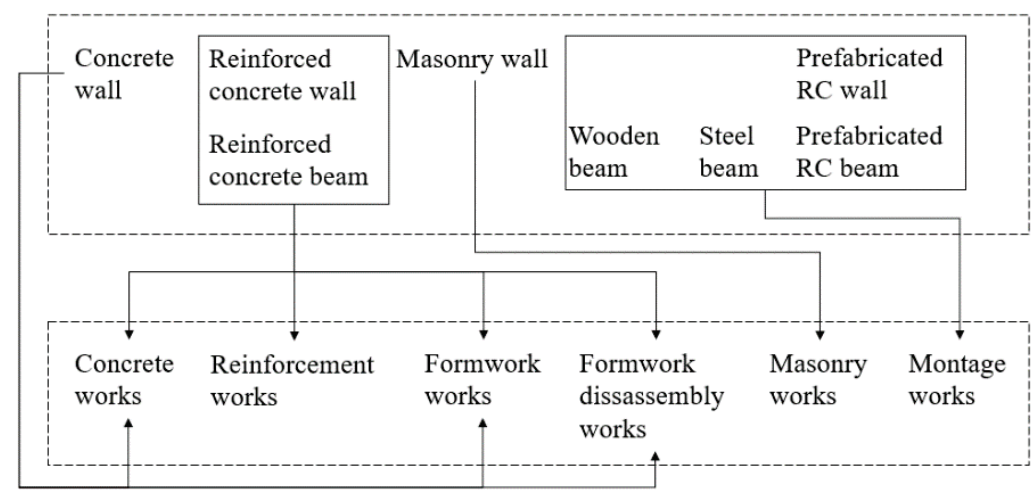

BIM model

elements with

material properties

Construction

activity work types

Figure 3 Link between BIM model and material types and construction activities

In this research, 61 construction activities needed for constructing 30 unique BIM model element/material combinations were identified. These 61 activities were then further divided into subactivities. It was soon discovered that a large number of construction activities have the same subactivities, which were identified as unique subactivity types. The activity "removal of formwork for reinforced concrete slabs" for example, consists of the following subactivities: Lowering the formwork by lowering the vertical prop's head, removal of the formwork boards, removal of the secondary and primary support beams and vertical props, cleaning the formwork, and transporting the formwork to the warehouse or the next place where it is needed. Formwork disassembly for beams, stairways and lintels all share these subactivities. A total of 256 sub-activities were identified. Further division of subactivities into job steps was not necessary, since construction plans are rarely planned in such level of detail and since hazards are generally not specified for such a detailed decomposition of work activities.

Connections between activities and subactivity types are presented in Fig. 4. The example shows that for some activities their subactivities are the same regardless of the 
element and in some cases even material. Concreting activity for a concrete column and for a reinforced concrete beam, for example, share the same subactivity types. In the case of formwork works, the same elements share only some of the subactivities, while having other unique ones.

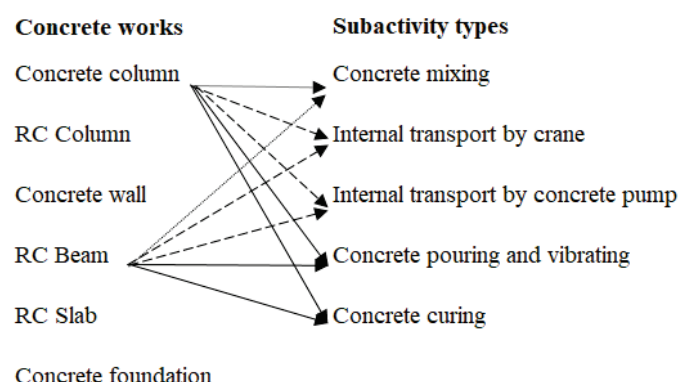

Concrete foundation

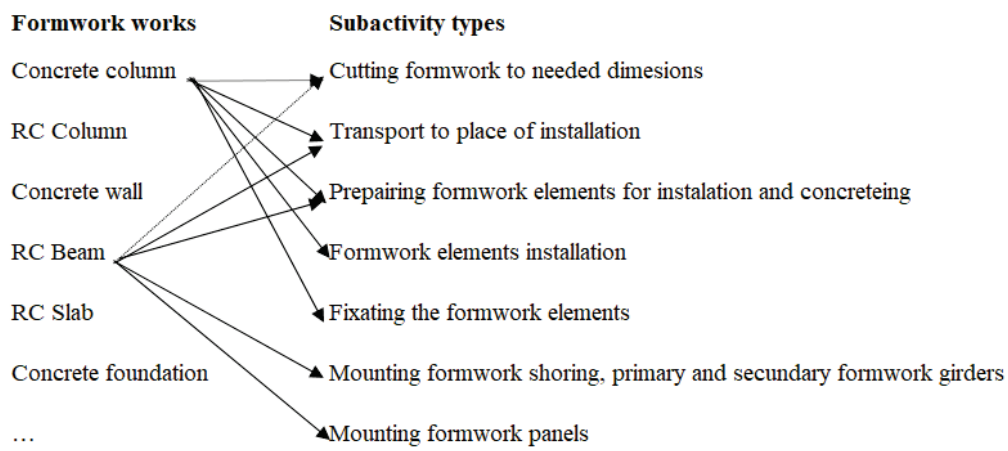

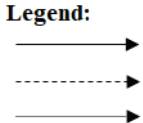

Subactivity always needed for element construction

One of the alternative subactivities needed for element construction

Subactivity not always present. Dependent on individual circumstance and/or construction technology

Figure 4 Link between construction activities and unique subactivity types

Activities currently included in the Construction process database are those that can be attributed to certain BIM model elements. There are however activities that do not directly result in construction of a BIM element, such as ground clearing, digging, trenching, preparatory works, transportation and unloading of materials, cleaning the construction site, and scaffold assembly and disassembly. These activities also cause hazards (some of which are already present in the Hazard information database) and will need to be added in the Construction process database as general construction activities in subsequent research.

$\mathrm{H} \& \mathrm{~S}$ documents named Risk assessments for places of work (described in detail in the following section) are primarily used as a source for identifying construction hazards in this research. They were however useful in this stage as well. They were used as a control mechanism to determine if all relevant activities were identified, since they also list all activities a worker conducts at a workplace. When the risk assessments were crossreferenced with the list of activities the workers perform on a construction site no new activities were identified, thus confirming that all construction activities relevant to the research were already included in the Database.

\section{CONSTRUCTION HAZARD DATA GATHERING PROCESS}

\subsection{Hazard Data Gathering Sources}

Hazards were collected to form a preliminary Hazard information database. The purpose of such a preliminary database was to see whether the planed integration with BIM models through the Hazard integration system (which is being developed in subsequent stage of this research) is possible. Therefore, the Database consists of not all potential hazards which may occur during the construction phase, but a sufficient number of hazards of all types. To gather the hazards, several types of sources were used.

According to Croatian legislation, specifically the Ordinance on health and safety on temporary and mobile construction sites [20], which is harmonised with EU Directive 92/57 EEC on the implementation of minimum safety and health requirements at temporary or mobile constructions sites [21], every construction site needs to have a site safety plan (Plan izvođenja radova in Croatian). The Ordinance prescribes the content of the plan and obligates the Health and Safety Coordinator to identify the hazards faced by the workers on each construction site and hazards which may be specific to that site. Therefore, these site safety plans, which display both global and specific hazards for each project were identified as a potential source to extract hazards for the Database.

The second source for hazard identification were risk assessments for places of work. Each employer is required by the Occupational Health and Safety Act [18] and by Ordinance on Risk Assessments [22] to identify all hazards for all places of work faced by his workers. This of course includes construction companies and their workers. The difference between these risk assessments and safety plans is that the risk assessment lists all activities a worker performs in a certain workplace and all the hazards the worker can face by performing his duties. The site safety plan, on the other hand, lists the hazards which workers working on a certain construction site may face. Neither of those two sources provides a one-to-one, or a one-to-many, link between an activity and the hazards which the activity poses. This fact complicated data gathering, since the hazards could not just simply be copied from the sources, but needed to be extracted, inferred, identified and concluded from unstructured data.

The third hazard source used for gathering hazards were books and scientific and professional papers on construction H\&S. A number of books, journals and conference papers dealing with construction safety show examples of safety hazards, safety (and design) suggestions, and other info which may be used to identify a hazard for the database. Books on construction safety also offer a wealth of potential hazards which may be used for the Database. This third source however, also does not provide a specific link between activities and the hazards they cause.

\subsection{The Need for a Database}

The fact that such documents which link specific activities to specific hazards they face do not exist, amplifies the need for a database such as the one developed in this research. Hazard gathering sources used in the 
research are too general to be useful for specific hazard identification. They are used to generally identify the hazards the workers may be exposed to and to globally plan for prevention measures, mostly personal protective equipment.

There is no construction hazard data source describing potential hazards in ways such as: "By working on formwork assembly a carpenter: may injure himself by cutting his finger while cutting wood; can hit himself on the hand with a hammer while assembling formwork plates; a formwork scaffold may fall and injure the worker; can cut his hand on the placed rebar;..." The Database developed in this research provides exactly such a connection between activities and hazards and enables automated hazard identification for every BIM model element and for every construction activity included in the Database.

An additional important feature of the Database is that it not only contains the hazards resulting from accidents, but also the hazards which result in work related illnesses. Almost all of the literature reviewed for this research focuses on the safety aspect of Health and Safety and disregards health issues of construction workers caused by professional illnesses developed while working on the construction sites.

\subsection{Sample}

Construction site safety plans were gathered from two sources: the largest construction companies in Croatia and from Health and Safety Coordinators. The plans were chosen to be representative of a wide variety of construction projects, but were mostly focused on large construction projects, featuring many different construction activities and hazards. On the other hand, since small construction sites may have some specific hazards, they too were included in the sample. In total, 27 site safety plans were collected and processed to gather construction hazards.

The plans included the construction of a hospital, hotels, residential buildings, a supermarket, an office building, a school, an industrial complex, and other buildings which have some discerning differences from the others, such as a completely precast concrete structure, or special works which are needed for the building's construction (for example, the top-down method). To further improve the chance of identifying a large number of hazards, other building types were included in the research which are not in the current research scope, such as a road, a bridge, an overpass, an agglomeration, a hydroelectric power plant reconstruction, TV tower reconstruction and construction and geotechnical works on preventing a landslide.

Some of the plans gathered from the contractors were made "in house" by the construction companies' own construction Health and Safety Experts, while others were made by external Health and Safety Coordinators ensuring variety in the sample, opinion and experiences. The rest of the site safety plans were collected directly from Health and Safety Coordinators working on the market as freelancers.

\begin{tabular}{|c|c|c|c|c|c|c|}
\hline \# & $\begin{array}{l}\text { Site safety plan / } \\
\text { Risk assessment }\end{array}$ & $\begin{array}{c}\text { Number of } \\
\text { hazards } \\
\text { identified }\end{array}$ & Project type & $\begin{array}{l}\text { Project } \\
\text { size* }^{*}\end{array}$ & $\begin{array}{c}\text { Source of the } \\
\text { risk assessment }\end{array}$ & $\begin{array}{c}\text { Made by the } \\
\text { construction } \\
\text { companies' or } \\
\text { an external } \\
\text { H\&S expert }\end{array}$ \\
\hline 1 & Site safety plan & 68 & $\begin{array}{l}\text { Commercial and } \\
\text { residential building }\end{array}$ & Large & $\begin{array}{l}\text { Construction } \\
\text { company }\end{array}$ & Internal \\
\hline 2 & Site safety plan & 17 & Hospital & Large & $\begin{array}{l}\text { Construction } \\
\text { company }\end{array}$ & Internal \\
\hline 3 & Site safety plan & 4 & $\begin{array}{l}\begin{array}{l}\text { School gym with a } \\
\text { swimming pool }\end{array} \\
\end{array}$ & Large & $\begin{array}{l}\text { Construction } \\
\text { company }\end{array}$ & Internal \\
\hline 4 & Site safety plan & 7 & Commercial & Large & $\begin{array}{l}\text { Construction } \\
\text { company }\end{array}$ & Internal \\
\hline 5 & Site safety plan & 2 & Hospital reconstruction & Medium & $\begin{array}{l}\begin{array}{l}\text { Construction } \\
\text { company }\end{array} \\
\end{array}$ & Internal \\
\hline 6 & Site safety plan & 0 & $\begin{array}{l}\text { Commercial and } \\
\text { residential building }\end{array}$ & Medium & $\begin{array}{l}\text { Construction } \\
\text { company }\end{array}$ & Internal \\
\hline 7 & Site safety plan & 5 & Shopping centre & Medium & $\begin{array}{l}\text { Construction } \\
\text { company }\end{array}$ & Internal \\
\hline 8 & Site safety plan & 0 & $\begin{array}{l}\text { Commercial and } \\
\text { residential building }\end{array}$ & Large & $\begin{array}{l}\text { Construction } \\
\text { company }\end{array}$ & Internal \\
\hline 9 & Site safety plan & 4 & $\begin{array}{l}\text { Airport terminal } \\
\text { reconstruction }\end{array}$ & Large & $\begin{array}{l}\text { Construction } \\
\text { company }\end{array}$ & External \\
\hline 10 & Site safety plan & 3 & Residential building & Medium & $\begin{array}{l}\text { Construction } \\
\text { company }\end{array}$ & External \\
\hline 11 & Site safety plan & 2 & Hotel complex & Medium & $\begin{array}{l}\text { Construction } \\
\text { company }\end{array}$ & External \\
\hline 12 & Site safety plan & 10 & $\begin{array}{l}\text { State road with a bridge } \\
\text { and an overpass }\end{array}$ & Large & $\begin{array}{l}\text { Construction } \\
\text { company }\end{array}$ & Internal \\
\hline 13 & Site safety plan & 5 & $\begin{array}{l}\text { Water supply system } \\
\text { reconstruction and sewer } \\
\text { system construction }\end{array}$ & Large & $\begin{array}{l}\text { Construction } \\
\text { company }\end{array}$ & Internal \\
\hline 14 & Site safety plan & 0 & Residential building & Small & $\begin{array}{l}\text { Health and safety } \\
\text { coordinator }\end{array}$ & External \\
\hline 15 & Site safety plan & 0 & TV tower reconstruction & Small & $\begin{array}{l}\begin{array}{l}\text { Health and safety } \\
\text { coordinator }\end{array} \\
\end{array}$ & External \\
\hline 16 & Site safety plan & 0 & Landslide rehabilitation & Small & $\begin{array}{l}\begin{array}{l}\text { Health and safety } \\
\text { coordinator }\end{array} \\
\end{array}$ & External \\
\hline 17 & Site safety plan & 0 & $\begin{array}{l}\text { Hydroelectric power plant } \\
\text { reconstruction }\end{array}$ & Large & $\begin{array}{l}\text { Health and safety } \\
\text { coordinator }\end{array}$ & External \\
\hline 18 & Site safety plan & 0 & $\begin{array}{l}\text { Shopping centre and } \\
\text { residential }\end{array}$ & Large & $\begin{array}{l}\text { Construction } \\
\text { company }\end{array}$ & Internal \\
\hline 19 & Site safety plan & 0 & Commercial skyscraper & Large & $\begin{array}{l}\text { Construction } \\
\text { company }\end{array}$ & Internal \\
\hline 20 & Site safety plan & 0 & $\begin{array}{l}\text { Commercial and } \\
\text { residential building }\end{array}$ & Medium & $\begin{array}{l}\text { Construction } \\
\text { company }\end{array}$ & Internal \\
\hline 21 & Site safety plan & 0 & Hotel reconstruction & Large & $\begin{array}{l}\text { Health and safety } \\
\text { coordinator }\end{array}$ & Internal \\
\hline 22 & Site safety plan & 0 & $\begin{array}{l}\text { Partial demolition and } \\
\text { reconstruction of a hotel }\end{array}$ & Large & $\begin{array}{l}\begin{array}{l}\text { Health and safety } \\
\text { coordinator }\end{array} \\
\end{array}$ & Internal \\
\hline 23 & Site safety plan & 0 & Villa reconstruction & Medium & $\begin{array}{l}\text { Health and safety } \\
\text { coordinator }\end{array}$ & Internal \\
\hline 24 & Site safety plan & 0 & $\begin{array}{l}\text { Reconstruction of a tourist } \\
\text { villa and pool construction }\end{array}$ & Medium & $\begin{array}{l}\begin{array}{l}\text { Health and safety } \\
\text { coordinator }\end{array} \\
\end{array}$ & Internal \\
\hline 25 & Site safety plan & 0 & Refurbishment of a hotel & Medium & $\begin{array}{l}\begin{array}{l}\text { Health and safety } \\
\text { coordinator }\end{array} \\
\end{array}$ & Internal \\
\hline 26 & Site safety plan & 0 & $\begin{array}{l}\text { Construction of a beach } \\
\text { club, external pool and } \\
\text { beach refurbishment }\end{array}$ & Medium & $\begin{array}{l}\text { Health and safety } \\
\text { coordinator }\end{array}$ & Internal \\
\hline 27 & Site safety plan & 0 & $\begin{array}{l}\text { Construction of an } \\
\text { elementary school with a } \\
\text { sports gym and outdoor } \\
\text { sports playing field } \\
\end{array}$ & Medium & $\begin{array}{l}\text { Health and safety } \\
\text { coordinator }\end{array}$ & Internal \\
\hline 28 & Risk assessment & 17 & $\mathrm{~N} / \mathrm{A}$ & $\mathrm{N} / \mathrm{A}$ & $\begin{array}{l}\text { Construction } \\
\text { company }\end{array}$ & Internal \\
\hline 29 & Risk assessment & 7 & N/A & N/A & $\begin{array}{l}\text { Construction } \\
\text { company }\end{array}$ & External \\
\hline 30 & Risk assessment & 0 & $\mathrm{~N} / \mathrm{A}$ & $\mathrm{N} / \mathrm{A}$ & $\begin{array}{l}\text { Construction } \\
\text { company }\end{array}$ & External \\
\hline 31 & Risk assessment & 0 & $\mathrm{~N} / \mathrm{A}$ & $\mathrm{N} / \mathrm{A}$ & $\begin{array}{l}\text { Construction } \\
\text { company }\end{array}$ & External \\
\hline
\end{tabular}

Figure 5 Sample for identifying construction hazards and number of hazards

$$
\text { identified }
$$

It was soon discovered that site safety plans are extremely similar to each other regardless of the project type, project size and the H\&S Coordinator who made the plan. They were however an excellent source for hazard identification, with altogether 127 hazards identified out of 151 hazards identified in the first round. From the first plan, 68 hazards were identified, 17 hazards in the second plan, 4 in $3^{\text {rd }}, 7$ in $4^{\text {th }}, 2$ in $5^{\text {th }}, 0$ in $6^{\text {th }}, 5$ in $7^{\text {th }}, 0$ from the $8^{\text {th }}, 4$ from $9^{\text {th }}, 3$ from $10^{\text {th }}, 2$ from $11^{\text {th }}, 10$ from $12^{\text {th }}, 5$ from $13^{\text {th }}$ and 0 from all the rest of the site safety plans. A detailed and clear overview of the sample size and number of hazards identified from each of the site safety plans and risk assessments is presented in Fig. 5 After the last 14 site safety plans were examined and no new hazards were identified from them, it became evident that a point of diminishing returns had been reached. This means that even if more site safety plans were examined, the number of hazards identified would be highly disproportional to the effort input in the identification process. Similar reasoning was found in the research by Hallowell and Gambatese [23] when they stopped field observations after no new 
activities were observed in 16 continuous hours of observation.

The second source for gathering construction hazards, risk assessments for places of work varied significantly from one construction company to another, not necessarily by quality, but by presentation. These assessments included many documents from which the hazards could be identified, including: general information, list of dangerous machinery and substances, list of personal protective equipment required for each workplace, and one risk assessment had a list of previous injuries incurred by the workers. However, the best source from the assessments were the ARMOR forms (acronym of Analiza Radnih Mjesta i Opasnosti na Radu in Croatian, translated to English as Analysis of workplaces and dangers faced by workers). These forms list all the activities included in the job description for each workplace and hazards which the worker is faced with. Moreover, a risk assessment is given for each of the hazards and harms. A lot of the hazards previously identified in the site safety plans were again discovered in the risk assessments. Even though a large number of hazards were previously identified, 24 new hazards were identified from 4 risk assessments. First risk assessment yielded 17 new hazards, second yielded 7, third and fourth yielded no new hazards. Another good use of the risk assessments was to compare if the previously discovered hazards are mentioned in the risk assessments similarly as with construction activities in the previous section. A large overlap was found which confirmed that the hazards are indeed present and important.

Construction safety books and articles were the third construction hazard gathering source. The specific sources were chosen from the already researched literature for the literature review chapter. This source unfortunately yielded no new hazards. The main reason is that a large number of professional documents made specifically to identify potential hazards were processed first. However, the same as with risk assessments, it was useful to see that the previously mentioned hazards were mentioned again in the literature.

Work safety reports (Elaborat zaštite na radu in Croatian) were not used to gather hazard data since they are focused on the safety of the end-user of the building and on the maintenance of the building. This phase is currently outside of the research scope, since it focuses on Health and Safety of construction workers.

\subsection{Process of Identifying Hazards from the Resources}

First steps of identifying hazards were briefly touched upon previously in this section. The sources were gathered from both prominent contracting companies in Croatia and Health and Safety Coordinators with enough experience in the field. Since the regulation has only recently come into force and gained widespread adoption, it was determined that 2 or more years of experience working as a H\&S Coordinator or authorship of more than 5 health and safety plans for larger projects classify a person as an expert in the field. Employees working for the construction companies were Health and Safety specialists working in the construction industry. The position they hold in a large construction company validates them as experts in the field. Contacts with both H\&S Coordinators and specialists were made first through their company's management, followed by a personal telephone call to explain the request and to arrange a personal meeting. The data was gathered through June, July and August 2017.

During the meeting, a more comprehensive description of the planned System and Database was given, while answering any questions they may have had. Following a short discussion on their experience in the industry, the projects they worked on and issues they had faced, more detailed description of what would be expected of them in the scope of the research was given. First, their Health and Safety documents, risk assessments for places of work, site safety plans for some of their most complicated construction sites and any additional information or documentation which may be useful to the research was requested. All experts were extremely interested in the research and its application, and were glad to help out with their experience and documentation.

A small exception was one health and safety specialist who was away from office for an extended period of time and a meeting could not be organised. A telephone conversation was held featuring the same elements as face to face meetings and documents were received by email. The call lasted for about half an hour, while the interviews lasted for half an hour up to an hour.

After the initial documents were gathered, the following stage consisted of successively going through the gathered documentation. With no discerning difference between the site safety plans and risk assessments in the way of how to gather hazards, the plans were arbitrarily chosen to be the first source. The plans were read and parts of plans which explicitly contained a hazard or a hazard could be inferred from the text were highlighted and comment was made as to what hazard was identified. The process was repeated with all the plans and even if the hazard was repeated in many plans it still was marked. The same process was repeated with the risk assessments and the hazards sources from the literature.

Along with information for the database, the structure and contents of each database entry (data entry sheets) also needed to be defined. This step took place in parallel with going through the hazard information sources. The structure and contents were primarily compiled from the requirements of the System and the requirements placed upon the Database by the research (searchability, filterability ...). Another source for ideas on how to structure the data entry sheets were previous experiences from the literature and ideas gathered from studying the hazard gathering sources themselves.

Scope of this research is limited to only defining the requirements and other characteristics of the Database. Choosing the most appropriate database type for integration with BIM models is a technical, not a research problem. Database design and elements however still need to be displayed and explained. The simplest method to show how the data needs to be structured is using MS Excel which will mimic the hazard information sheets of the future Database. The hazards and activities were not therefore input in a database format, but rather manually entered in forms created in an MS Excel spreadsheet. An example of the initial hazard entry sheet is shown in Fig. 6. 


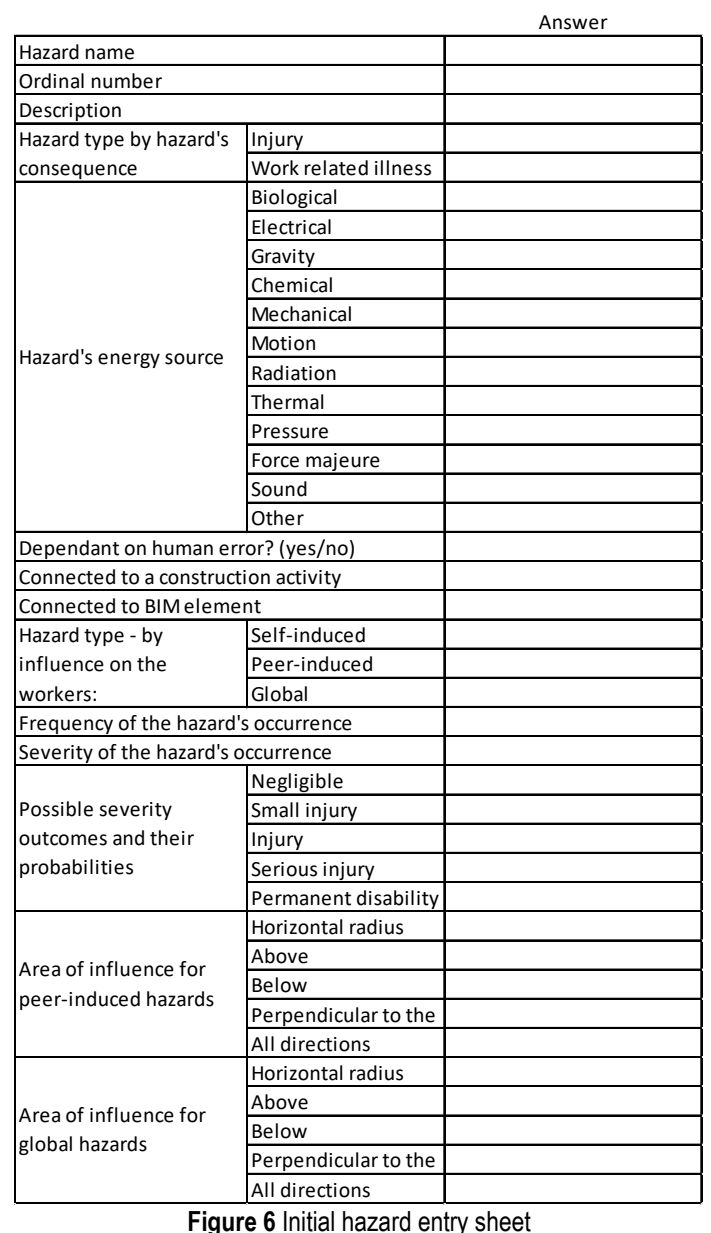

\subsection{Iterations of the Hazard Identification Process}

During the hazard identification process, a total of 151 hazards were identified. However, it was clear that some of the hazards were almost duplicate, could be merged or needed to be split from one another. Currently, some hazards present in the Hazard information database are not directly connected to activities in the Construction process database. They were not excluded because they can pose hazards on the workers working on the activities that are in the database and since the activities which pose these hazards are only momentarily outside of the research scope.

After completing the initial database, ideas for improvement were discovered. Some fields in the forms were found to be unimportant while others needed to be added, such as information whether the hazard is dependent on the location of the BIM model element (e.g. whether the element is at height, next to a leading edge, or below ground) and whether the hazard is dependent on the spatial characteristics of the BIM model element (e.g. the element's height which determines the need for temporary scaffolds). These changes were incorporated into the updated hazard entry sheet displayed in Fig. 7.

\begin{tabular}{|c|c|c|c|c|}
\hline \multirow{6}{*}{ 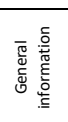 } & & & Answer & Comment \\
\hline & \multirow{2}{*}{\multicolumn{2}{|c|}{\begin{tabular}{|l} 
Ordinal number \\
Hazard name
\end{tabular}}} & & \\
\hline & \multirow{2}{*}{\multicolumn{2}{|c|}{\begin{tabular}{|l} 
Hazara name \\
Additional information \\
\end{tabular}}} & & \\
\hline & & & & \\
\hline & \multicolumn{2}{|l|}{ Injury } & & \\
\hline & \multicolumn{2}{|c|}{ Work related illness } & & \\
\hline \multirow{14}{*}{ 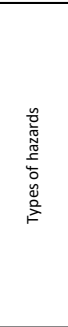 } & \multirow{11}{*}{$\begin{array}{l}\text { Hazard's energy } \\
\text { source }\end{array}$} & Biological & & \\
\hline & & Electrical & & \\
\hline & & Gravity & & \\
\hline & & Chemical & & \\
\hline & & Mechanical & & \\
\hline & & Motion & & \\
\hline & & Radiation & & \\
\hline & & Thermal & & \\
\hline & & Pressure & & \\
\hline & & Sound & & \\
\hline & & Other & & \\
\hline & \multirow{3}{*}{$\begin{array}{l}\begin{array}{l}\text { Hazard type - by } \\
\text { influence on the } \\
\text { workers }\end{array} \\
\end{array}$} & Self-induced & & \\
\hline & & Peer-induced & & \\
\hline & & Global & & \\
\hline \multirow{7}{*}{ 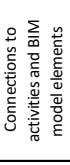 } & \multicolumn{2}{|c|}{ Global hazard source } & & \\
\hline & \multicolumn{2}{|c|}{ General construction hazard } & & \\
\hline & \multirow{2}{*}{\multicolumn{2}{|c|}{\begin{tabular}{|l|} 
Dependant on human error \\
Connected to a construction activity \\
\end{tabular}}} & & \\
\hline & & & & \\
\hline & \multicolumn{2}{|c|}{ Connected to BIM element type or material } & & \\
\hline & \multicolumn{2}{|c|}{ Dependent on BIM element's location } & & \\
\hline & \multicolumn{2}{|c|}{ Dependent on BIM element's spatial location } & & \\
\hline \multirow{7}{*}{ 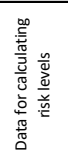 } & \multirow{2}{*}{\multicolumn{2}{|c|}{$\begin{array}{l}\text { Frequency of the hazard's occurrence } \\
\text { Severity of the hazard's occurrence }\end{array}$}} & & \\
\hline & & & & \\
\hline & \multicolumn{2}{|c|}{\begin{tabular}{|l|l|} 
Possible severity & Negligible \\
\cline { 2 - 2 }
\end{tabular}} & & \\
\hline & \multirow{4}{*}{$\begin{array}{l}\text { outcomes and } \\
\text { their } \\
\text { probabilities }\end{array}$} & Small injury & & \\
\hline & & Injury & & \\
\hline & & \begin{tabular}{|l|} 
Serious injury \\
\end{tabular} & & \\
\hline & & Permanent disability or death & & \\
\hline \multirow{10}{*}{ 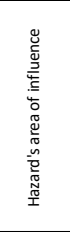 } & \multirow{5}{*}{$\begin{array}{l}\text { Area of influence } \\
\text { for peer-induced } \\
\text { hazards }\end{array}$} & Horizontal radius & & \\
\hline & & Above & & \\
\hline & & Below & & \\
\hline & & \begin{tabular}{|l} 
Perpendicular to the work front \\
\end{tabular} & & \\
\hline & & All directions & & \\
\hline & \multirow{5}{*}{$\begin{array}{l}\text { Area of influence } \\
\text { for global hazards }\end{array}$} & Horizontal radius & & \\
\hline & & Above & & \\
\hline & & Below & & \\
\hline & & Perpendicular to the work front & & \\
\hline & & All directions & & \\
\hline
\end{tabular}

Figure 7 Updated hazard entry sheet

Moreover, two hazard subtypes of global hazards were identified as important and additional information on whether the hazard meets the criteria of these subtypes was needed to be added to the hazard entry sheet. The first subtype is "hazards with a global source" and the second subtype are the "general site hazards". Their "globality" is manifested differently. The global source hazard is global in the sense that a large number of activities can cause the hazard. It is known who is exposed to the hazard, but it is not known exactly which activity will cause the hazard to occur. General construction hazards on the other hand were identified as hazards to which all workers are exposed just by working on the construction site.
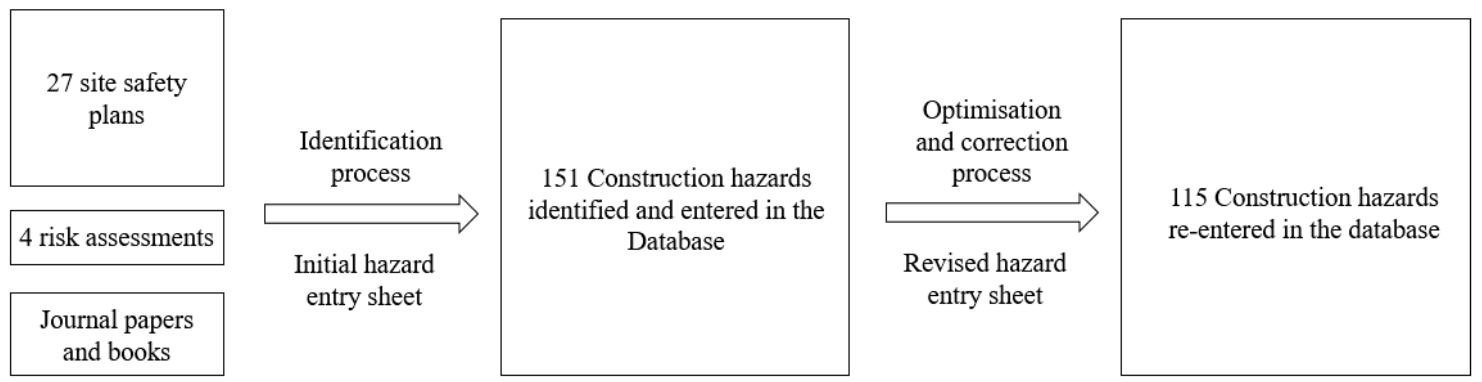

Figure 8 Hazard identification and database optimisation process 
Regarding the database's content, some almost duplicate entries were discovered (e.g. noise hazard from working on a saw and noise hazard while working on cutting metal are basically the same hazard, the only difference being the machine producing the sound) and since new information was needed to be added in the forms it was needed to refine the Database. During the second iteration, some hazards were merged, some were split, and some were expanded and improved to include more information. They were also revised if an error was made in the first iteration regarding the hazard source, hazard type, area of influence, or other, enabled by a more complete knowledge of construction hazards. Final version of the database lists 115 construction hazards. Entire process of hazard identification and subsequent optimisation is presented in Fig. 8.

\subsection{Grouping Hazards and Connecting them to Activities}

After the hazard entries were optimised, the final step was to connect the hazards with construction activities. To that end, the hazards were first rearranged and grouped to simplify linking with the activities which produce the hazards. They were grouped into the following categories:

- Hazards resulting from formwork works;

- Hazards resulting from reinforcement works;

- Hazards resulting from concreting;

- Hazards resulting from masonry works;

- Hazards resulting from earth works;

- Hazards resulting from montage works;

- Global hazards;

Transportation, crane and warehouse related hazards;

- General construction hazards;

- Hazards dependant on the location of BIM model element;

Physiological hazards;

- Hazards resulting from construction machinery and equipment;

- Other hazards.

The next step was manually adding construction activities to the hazards. This is a critical step since errors can cause hazards not to be identified on the construction site. For the purpose of this research, the hazards and activities were linked by adding the code of all related construction activities in the hazards' entry sheets. In later research, the hazards and activities will be entered in such a way that it enables fulfilling all requirements placed upon the Database. Further disclaimer pertains to the actual connections. While great care was taken when connecting the hazards and activities, errors have possibly occurred. Some hazards were perhaps not connected to all activities which cause them (false negative), and on the other hand some activities might be connected to hazards they do not cause (false positive). Since this stage of the Database is to be used only for research purposes and to provide answers to whether connections between activities and hazards are possible, high degree of accuracy is not required. For use in real world, the Database needs to be thoroughly checked by relevant experts to determine that all hazards and activities were identified and correctly linked.

\section{CONCLUSION}

The paper presented a method of how the Construction hazards database was created and how construction hazards and activities were extracted and input in the Database. To reiterate, the Database structure was, for the current stage of the research, defined as a set of Excel tables which mimic the hazard information sheets of the future final version of the Database. The sheets themselves were created based on the information needed by the Hazard integration system, on the previous best practices from the literature and on the information from the sources used to gather construction hazards.

Section 2 of the paper described in detail how construction activities were identified, while section 3 focused on the hazards. Sources used for identifying hazards were documents which contractors are legally required to possess: work assessments for places of work and Health and Safety plans. Hazard information was extrapolated from these sources and each of the identified hazards was entered in the Database along with all associated necessary information.

The process described in the paper is an important prerequisite in the goal of automating construction hazard identification using BIM models. Goal of the research presented in the paper was not to identify all hazards and activities present on the construction site, but to present a method of how it can be done. Further work is needed to be sure that all possible hazards and activities are included in the database.

A total of 115 hazards were identified from the documentation and stored in the Construction hazards database, as well as 61 construction activities and 256 subactivities needed to construct BIM model elements. However, the focus was mostly on hazards and activities needed for constructing only structural elements of a building, since their connection to BIM model elements is the most straightforward. Not included are the activities and hazards for finishing and installation works. Moreover, current focus is on high-rise construction with other construction project types disregarded in the current stage. Conceptually, the process of hazard identification is identical for finishing and installation works, as well as across other project types and although they are currently outside the scope of both the paper and the thesis [16], they are planned to be included in later phases of the research. Further work in this stage of the research also includes defining all remaining characteristics of the Database and how it will be connected to the Hazard integration system.

\section{REFERENCES}

[1] International Labor Organization. (2013). World Day for Safety and Health at Work 2013. Retrieved from www.ilo.org/safework/events/meetings/WCMS_204594/lan g--en/index.htm

[2] International Labor Organization. (2005). World day for safety and health at work 2005: a background paper. Retrieved from http://www.ilo.org/public/english/bureau/ inf/dowload/sh_background.pdf

[3] Raheem, A. A. \& Hinze, J. W. (2014). Disparity between construction safety standards: A global analysis. Safety Science, 70, 276-287. https://doi.org/10.1016/j.ssci.2014.06.012

[4] Zhang, S. (2014). Integrating safety and BIM: automated construction hazard identification and prevention. (Doctor of Philosophy), Georgia Institute of Technology. 
[5] Zhou, Z., Goh, Y. M., \& Li, Q. (2015). Overview and analysis of safety management studies in the construction industry. Safety Science, 72, 337-350. https://doi.org/10.1016/j.ssci.2014.10.006

[6] Gambatese, J., Hinze, J., \& Haas, C. (1997). Tool to Design for Construction Worker Safety. Journal of Architectural Engineering, 3(1), 32-41. https://doi.org/10.1061/(ASCE)1076-0431(1997)3:1(32)

[7] Rozenfeld, O., Sacks, R., \& Rosenfeld, Y. (2009). 'CHASTE': construction hazard assessment with spatial and temporal exposure. Construction Management and Economics, 27(7), 625-638. https://doi.org/10.1080/01446190903002771

[8] Workcover. (2011). CHAIR Safety in Design Tool. New South Wales: WORKCOVER

[9] Rozenfeld, O., Sacks, R., Rosenfeld, Y., \& Baum, H. (2010). Construction Job Safety Analysis. Safety Science, 48(4), 491-498. https://doi.org/10.1016/j.ssci.2009.12.017

[10] Whyte, J., Sacks, R., Zhou, W., \& Haffegee, A. (2013). Building safely by design - Using digital design models to improve planning for safe construction. Retrieved from Institution of Occupational Safety and Health

[11] Sacks, R., Whyte, J., Swissa, D., Raviv, G., Zhou, W., \& Shapira, A. (2015). Safety by design: dialogues between designers and builders using virtual reality. Construction Management and Economics, 33(1), 55-72. https://doi.org/10.1080/01446193.2015.1029504

[12] Zhang, S., Boukamp, F., \& Teizer, J. (2015). Ontology-based semantic modeling of construction safety knowledge: Towards automated safety planning for job hazard analysis (JHA). Automation in Construction, 52, 29-41. https://doi.org/10.1016/j.autcon.2015.02.005

[13] Zhang, S., Teizer, J., Lee, J.-K., Eastman, C. M., \& Venugopal, M. (2013). Building Information Modeling (BIM) and Safety: Automatic Safety Checking of Construction Models and Schedules. Automation in Construction, 29, 183-195. https://doi.org/10.1016/j.autcon.2012.05.006

[14] Bansal, V. K. (2011). Application of geographic information systems in construction safety planning. International Journal of Project Management, 29(1), 66-77. https://doi.org/10.1016/j.jproman.2010.01.007

[15] Tixier, A. J. P., Hallowell, M. R., Rajagopalan, B., \& Bowman, D. (2016). Automated content analysis for construction safety: A natural language processing system to extract precursors and outcomes from unstructured injury reports. Automation in Construction, 62, 45-56. https://doi.org/10.1016/j.autcon.2015.11.001

[16] Mihić, M. (2018). Incorporation of Health and Safety into Building Information Modelling through Hazard Integration System. (PhD thesis), Faculty of Civil Engineering, Zagreb, Croatia.

[17] Cerić, A. (2014). Upravljanje rizicima. Paper presented at the Hrvatski graditeljski forum, Zagreb, Croatia.

[18] The Occupational Health and Safety Act, (2014). NN $51 / 2008$, Republic of Croatia, Official Gazette.

[19] NNC Limited. (2003). The development of a knowledge based system to deliver health and safety information to designers in the construction industry. In Research Report 173 (pp. 89). Norwich, UK: Health \& Safety Executive.

[20] Ordinance on health and safety on temporary and mobile construction sites, (2008). NN 112/2014, Republic of Croatia, Official Gazette.

[21] Directive 92/57/EEC on the implementation of minimum safety and health requirements at temporary or mobile construction sites, (1992). The Council of the European Communities: Brussels.

[22] Ordinance on risk assessments, (2014). Republic of Croatia, Official Gazette.
[23] Hallowell, M. \& Gambatese, J. (2009). Activity-Based Safety Risk Quantification for Concrete Formwork Construction. Journal of Construction Engineering and Management, 135(10), 990-998. https://doi.org/10.1061/(ASCE)C0.1943-7862.0000071

\section{Contact information:}

Matej MIHIĆ, MCEng

(Corresponding author)

University of Zagreb Faculty of Civil Engineering,

Kačićeva 26, 10000 Zagreb, Croatia

mmihic@grad.hr

Anita CERIĆ, prof., PhD, MCEng

University of Zagreb Faculty of Civil Engineering,

Kačićeva 26, 10000 Zagreb, Croatia

anita@grad.hr

Ivica ZAVRŠKI, prof., PhD, MCEng

University of Zagreb Faculty of Civil Engineering,

Kačićeva 26, 10000 Zagreb, Croatia

zavrski@grad.hr 